\title{
DISCUSSION
}

\section{Influence of soil structure and stress history on the soil-water characteristics of a compacted till}

\author{
S. K. VANAPAlli, D. G. FREDLUND and D. E. PUFAHL (1999). Géotechnique 49, No. 2, 143-159
}

A. Vatsala and B. R. Srinivasa Murthy, Indian Institute of Science

The authors have presented very useful experimental data on soil-water characteristics which can throw light on many aspects. We would like to discuss two issues

(a) the relationship between suction and water content or degree of saturation

(b) the air-entry value.

Although the authors do not seem to attach much importance to the section on suction versus water content relationships, we would like to highlight certain points using the data presented. It is generally accepted in the field of unsaturated soils that suction is related to the degree of saturation or water content, which may not be true for all conditions and needs to be examined further. The authors' data show that there is no unique relationship between suction and degree of saturation but only a similar trend of decreasing suction with increase in degree of saturation which exists for any given density. The fact that we can apply any magnitude of suction (up to the air-entry value) to a saturated highly plastic clay, the soil still remaining saturated, also suggests that there may not be a unique relationship between suction and degree of saturation. However, the data show an almost unique relationship between suction and water content, even for different densities.

We feel that for a freshly compacted soil, the magnitude of suction depends mainly on the applied compactive stress and only incidentally on the water content or degree of saturation. The authors' test results can be re-examined in terms of the compactive effort. The samples were prepared at three different densities or void ratios of $0.58,0.52$ and 0.545 (corresponding to dry-of-, at-, and wet-of-optimum states on a standard compaction curve) but with varying water contents as shown in Fig. 18. At any given specific void ratio, say $0 \cdot 545$, the value of suction is found to decrease with increasing water content, and hence also with increasing degree of saturation. This is only because it requires a greater compactive effort to compact a soil with lower water content to the given density than to compact a soil with a higher water content. Compactive effort being higher, the induced suction will be higher. But the same need not be true for samples with different densities. The authors' data do show a nearly unique relationship between suction and water content, irrespective of the density. Unfortunately, the range of densities chosen is very small $(e=0.52-0.58)$ and no large variation is seen. Instead, if soil samples were prepared with wider variation in density, as shown by the triangular points in Fig. 18, all at the same water content, they would have shown distinctly different suction values; that is, at a given water content, the state with maximum density would have been subjected to the highest compactive stress or energy and hence would have higher suction induced in spite of having a higher degree of saturation when compared to a specimen of lower density. (We had measured a suction of $242 \mathrm{kPa}$ for a sample statically compacted to $400 \mathrm{kPa}$ and a suction of $367 \mathrm{kPa}$ for the sample compacted to $600 \mathrm{kPa}$, by the axis-translation technique. Both samples had an initial mixing water content of $14 \cdot 1 \%$. The soil used was a silty clay with an LL of $38.4 \%$ and OMC of $16 \%$.)

However, for the wet-of-optimum states, the relationship between induced suction and compactive effort may show
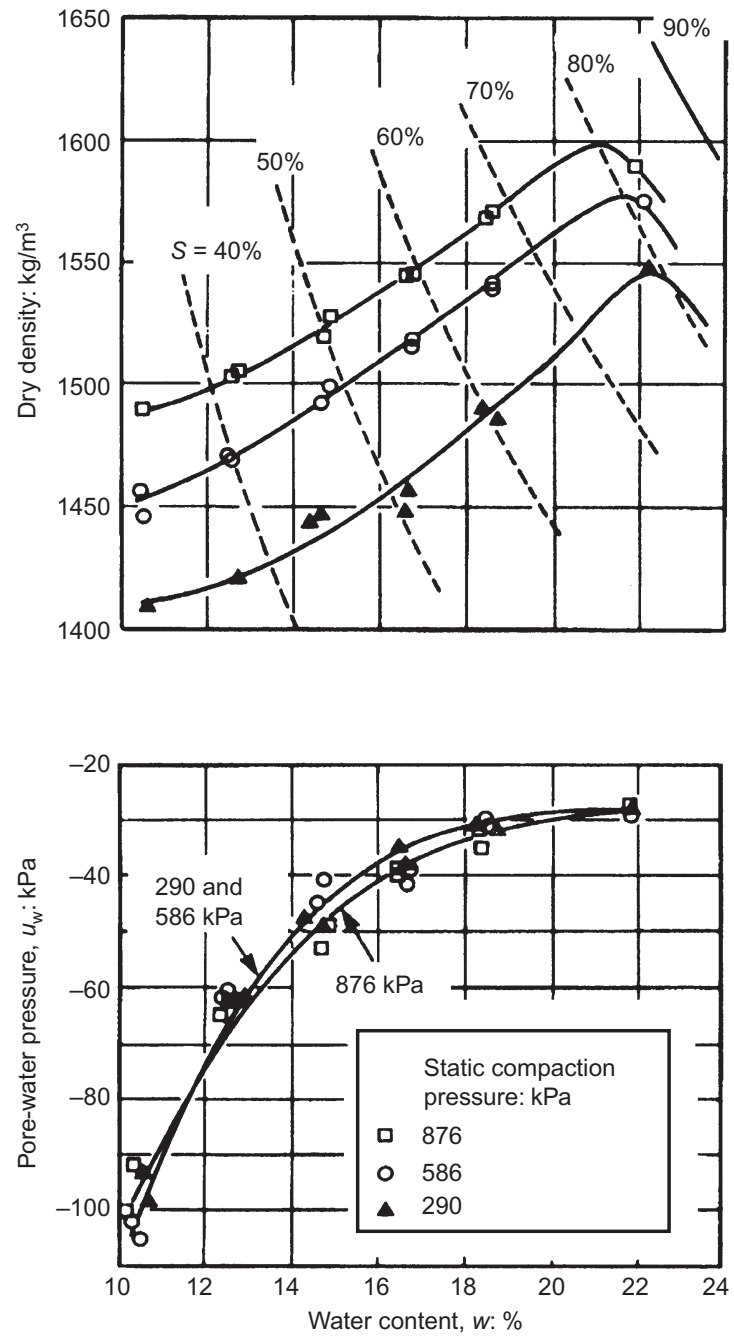

Fig. 19. Negative pore-water pressure measurements on compacted specimens using the axis-translation technique (from Olson \& Langfelder, 1965)

deviations, because for such states the applied compactive effort might not have been fully effective, part of it being carried by built-up positive pore-water pressures. Suction would in that case correspond to the actual (unknown) effective stress within the sample during compaction and not the applied compactive stress. Thus, it appears that it is the compactive stress or energy that influences the magnitude of suction in compacted soils, and not the water content or the degree of saturation.

Regarding the air-entry value, the authors have highlighted that it is influenced by the soil structure and the stress history. Air-entry value is lower (with a steeper water discharge) for soil states compacted dry of optimum than for wet of optimum. Airentry value is shown to increase with increase in the prestress for dry-of-opimum states but is not affected much for wet-ofoptimum states. It is said that the aggregated macro-structure governs the soil-water characteristics for dry-of-optimum states and that micro-structure governs the same for wet states. 
We feel that there is no big difference in the microstructure of dry- and wet-of-optimum states. Both dry- and wet-ofoptimum states and even saturated slurry consolidated states have macro-pores (although relatively larger in dry states) as shown by several recent mercury porosimetry and scanning electron microscopy (SEM) studies. The only difference may be that there are larger air pores in the dry state at the same given void ratio. Now, accepting that dry-of-optimum states have larger air pores, this should not affect the air entry value for a fine-grained clayey soil, because, upon saturation (under a nominal pressure as was done in the present study), these large pores would not remain but would collapse to the same size as that of the maximum possible water pore in a slurry consolidated soil at the given stress level; that is, there cannot be a water pore in a saturated compacted state larger than the pores in a slurry consolidated state under the same stress state. This point is very well proved by the fact that a loose compacted state, upon inundation, collapses to the same state as a slurry consolidated state and follows the slurry compression path for further loading. Thus, for a clayey soil, any saturated sample should have the same air-entry value as that of a slurry consolidated state.

Moreover, it is reasonable that even an unsaturated state has the same air-entry value, although in terms of degree of saturation it may follow a different water characteristic path. This is because, in an unsaturated state, it is quite possible that the existing air volume expands under the applied suction, but air cannot replace water in any case for suctions less than the air-entry value (of slurry state). Thus, even if a decreasing degree of saturation is observed with increase in suction, it may not necessarily mean that desaturation of water pores is occurring. However, in the present paper, all the samples were initially saturated and hence, theoretically, all of them should have shown the same air-entry values as the wet-of-optimum sample. There could be two reasons for the data showing deviation from this behaviour: $(a)$ the volume changes during suction applications may not be negligible as assumed; or $(b)$ the initial degree of saturation of the samples may be less than $100 \%$. Although the authors say that they do not expect considerable volume changes for applied suctions for this soil type, this may not be true for all conditions. There are reasons why the dry-of-optimum samples show greater volume changes: because of their initially larger void ratio, and more importantly because of the freshly formed water pores by way of saturation of air pores, which may exhibit virgin compressibility. On the other hand, the wet states were almost saturated before, and all the water volume had been compressed to a much higher stress in the process of self-compaction. Thus the applied suctions would be somewhat akin to reloading and hence have negligible compressibility. Thus it is likely that the results are showing deviation from the actual behaviour whenever the assumption of zero volume change is not true. It is obvious that for the same data, if some compression is assumed to have occurred for the early applied suctions, the curves would move closer to the curves for the wet-ofoptimum states.

This might also be one of the reasons for the observed increase in resistance to desaturation with increase in prestressing for the dry samples. The soil being already compressed during prestressing would show lesser or negligible compression during further suction applications. The assumption of zero volume change would then be more valid, hence the results closer to the true value. For wet-of-optimum samples, prestressing may not have any effect because in this case, even for zero prestress, the soil was not significantly compressible.

Secondly, as discussed earlier, an initially unsaturated soil can show a decreasing degree of saturation with applied suction because of possible expansion of air volume without replacement of water volume by air. It appears that the initial degree of saturation was not measured for all the samples, but only for some trial samples. It is quite difficult to saturate compacted specimens, even after $36 \mathrm{~h}$ of soaking, unless water is forced in by giving a positive head depending on the initial conditions.
Hence it is necessary to examine more closely the initial degree of saturation of the samples.

Finally, it is unfortunate that the authors have chosen a lowplastic clay with a very low air-entry value for this study. If similar data were available on a more plastic clay such as Regina clay, it might have clarified these issues.

\section{Authors' reply}

The authors appreciate the interest that the discussers have shown in the research paper. The two main questions raised by the discussers deal with

(a) the matrix suction and water content relationship of individually compacted specimens

(b) the air-entry value of the soil-water characteristics described in the paper.

The discussers suggest that for a compacted soil (i.e. individually compacted specimens), the magnitude of matrix suction depends on the applied compactive stress and only incidentally on the water content or degree of saturation. Several investigators have reported results that are contrary to the discussers' suggestion. In other words, laboratory test results have confirmed that there is a rather unique relationship between the 'as-compacted' water contents and matrix suction. Olson \& Langfelder (1965) tested five soils with different static compaction pressures ranging between 290 to $876 \mathrm{kPa}$. The applied static compaction pressure was shown to have essentially no influence on the relationship between 'as-compacted' water content and matrix suction. Fig. 19 shows typical results of Peorian loess tested by Olson \& Langfelder (1965).

The unique relationship between the water content and matrix suction value (i.e. negative pore-water pressure) appears to be reasonable from the theory of undrained loading on an unsaturated soil. The B pore pressure parameter for unsaturated soils is relatively low for a large range of water contents. Campbell (1973) studied specimens compacted at and below optimum conditions and showed a small increase in pore-water pressures even when subjected to confining pressures as high as $7000 \mathrm{kPa}$. Skempton (1954) also showed that the B pore pressure parameter is around $0 \cdot 1-0 \cdot 2$ for specimens compacted at degrees of saturation lower than $90 \%$. In other words, the matrix suction in the compacted specimens is dependent on the water content rather than the applied static compaction pressure for a large range of water contents. Similar unique relationships as shown in Fig. 19 were observed for all other soils tested by Olson \& Langfelder (1965).

The authors also cite several other investigators who reported similar trends in results with tills and Regina clay that represent clays of low and high plasticity respectively (Mickleborough, 1970; Pufahl, 1970; Krahn \& Fredlund, 1972; Weimer, 1972). Croney \& Coleman (1954) reported similar conclusions based on their studies on a silty clay and a London clay.

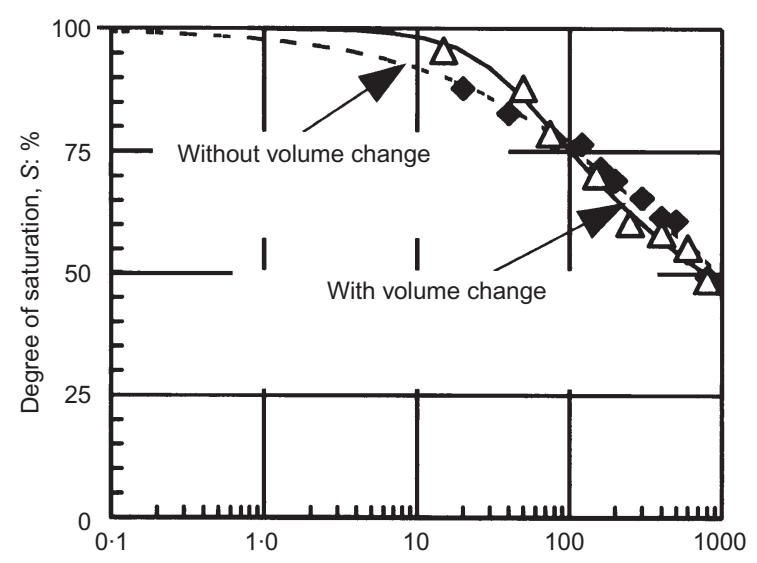

Fig. 20. Comparison of soil-water characteristics of specimens compacted at dry-of-optimum conditions measured with and without volume changes with respect to suction 
In the research described in the paper, matrix suctions were determined for 21 individually compacted specimens that were $21 \mathrm{~mm}$ in diameter, using the axis-translation technique (Fig. 17 and Table 4). In addition to the above tests, matrix suctions were also measured using another 21 individually compacted specimens. These specimens were $100 \mathrm{~mm}$ diameter $\times 10 \mathrm{~mm}$ thick (Vanapalli, 1994). Similar trends in the results as reported in Fig. 17 were obtained. The individually compacted specimens prepared for measuring matrix suctions were wrapped in Saran paper and placed in a humidity-controlled room for a period of $48 \mathrm{~h}$ prior to measuring matrix suction. This procedure was done to attain equilibrium water content and matrix suction values in the specimens.

The authors would like to emphasise that there indeed appears to be a unique relationship between matrix suction and the 'as-compacted' water content for the tested Indian Head till (i.e. for individually compacted specimens) and for the range of water content between 12.5 and $19 \cdot 2 \%$ and a void ratio range of 0.52 and 0.58 (i.e. dry density of $1.73-1.80 \mathrm{Mg} / \mathrm{m}^{3}$ ) (Fig. 17).

The discussers report results of two tests performed using freshly compacted specimens. Based on these results, the discussers conclude that the magnitude of matrix suction of compacted soils mainly depends on the applied compactive stress and only incidentally on the water content or degree of saturation'. The discussers further comment that their own observations may not be valid for specimens compacted with initial water contents that represent wet-of-optimum conditions. The results reported by the discussers are interesting; however, the conclusion drawn by the discussers is based on very limited data. More test results are necessary on different soils before a valid 'general conclusion' can be stated.

The discussers express the idea that at the same stress levels, pore sizes in specimens compacted at or dry of optimum will be identical to pore sizes as in a slurry consolidated soil. They state that this is a proven fact but do not provide any references from the published literature. It is difficult to make any further comment on the discussers' statement. In fact, the structure of a compacted soil has been known to depend on the initial water content and has been found to be different to that of a slurried soil (Lambe, 1958; Seed \& Chan, 1959; Seed et al., 1960; Benson \& Daniel, 1990; Elsbury et al., 1990).

The discussers expressed the view that a particular soil, irrespective of its stress history and structure, should have a unique air-entry value. They further attribute the variations in soil-water characteristics reported in the paper to likely volume changes in the specimens with respect to suction, and to the degree of saturation in the specimens being less than $100 \%$. The discussers should note that the procedures used for measuring the soil-water characteristics described in the paper were in accordance with standard procedures (ASTM, 1993). Based on trial tests, a test procedure was established to ensure the initial degree of saturation in the specimens used for measuring soilwater characteristics was close to $100 \%$. The authors have taken care in establishing a test procedure for measuring the soilwater characteristics that is consistent with the standard procedures. These details were discussed in the paper.

The authors have also compared the soil-water characteristics with and without volume changes for a specimen compacted at an initial water content dry of optimum. The soilwater characteristics were measured for a suction range $0-1000 \mathrm{kPa}$ (Vanapalli, 1994). These results are shown in Fig. 19. From a practical perspective, no significant changes were observed in the soil-water characteristics determined by using both of these methods. The literature suggests that statically compacted specimens of clays with low plasticity are volumetrically stable against suction increases (Sridharan et al., 1971; Badger \& Lohnes, 1973; Ahmed et al., 1974). The authors agree that for highly plastic clays there may be volume changes with respect to suction. Predominant volume changes for highplastic clays occur mainly in the boundary effect zone (i.e. between fully saturated condition and the air-entry value of the soil) (Russam, 1958; Fredlund, 1964).

Several investigators have shown that soil specimens com- pacted at initial dry-of-optimum water content conditions have lower air-entry values in comparison to specimens compacted wet of optimum (Tinjum, 1995; Wang \& Benson, 1995; Tinjum et al., 1997). Along similar lines, soils compacted with lower densities have lower air-entry values in comparison to specimens compacted with higher densities (Croney \& Coleman, 1954). Their studies also show that the air-entry value for both compressible and incompressible materials is dependent on the pore size distribution. Studies by Barden \& Sides (1970) are also consistent with these observations. Similar observations can be derived from soil fabric studies using mercury intrusion porosimetry and SEM tests (Bhasin \& Lovell, 1981; Prapaharan et al., 1985; Delage et al., 1995). The pore size distribution for the same soil can be different due to differences in initial water content, stress history and compactive energy. The air-entry value of an initially slurried, then consolidated soil is also different from an in situ soil. Comprehensive experimental studies support these observations (Croney \& Coleman, 1954).

The authors would like to comment on several other statements made by the discussers.

Firstly, the discussers state that the authors have not given importance to the section on the suction versus water content relationships for individually compacted specimens in the paper. They also state that it is unfortunate that the authors have chosen to use a low-plastic clay in the study instead of a highly plastic clay.

This research was aimed at understanding the behaviour of an unsaturated soil that establishes the theory and character of low-plasticity clays such as the Indian Head till used in this study. Soils with grain size and index properties similar to Indian Head till are typical of sandy clay deposits found extensively in Western Canada and other glaciated regions of the world that are commonly used as a construction material.

Secondly, the discussers point out that the soil-water characteristic relationship is not unique because the soil is fully saturated up to the air-entry value. The authors agree with this statement that is well-established in the literature (Croney \& Coleman, 1954; Russam, 1958; Hillel, 1982). This aspect is discussed in the paper and can also be observed from the experimental data shown in Figs 2, 6, 7 and 8. The effects of hysterisis and scanning curves further substantiate the foregoing statement. However, hysterisis and scanning curve effects were not discussed, as they were not the objectives of the study.

\section{REFERENCES}

Ahmed, S., Lovell, C. W. \& Diamond, S. (1974). Pore sizes and strength of compacted clay. Journal of Geotech. Engng Div., ASCE, 100, No. GT4, 407-426.

ASTM (1993). Test method for capillary-moisture relationships for coarse- and medium-texture soils by porous plate apparatus. ASTM D2325-68 (1981). In Annual book of ASTM standards, vol. 4.08, pp. $301-303$.

Badger, W. W. \& Lohnes, R. A. (1973). Pore structure of friable loess. HRB Record, 429, 14-25.

Barden, L. \& Sides, G. R. (1970). Engineering behavior and structure of compacted clay. Journal of SMFE, ASCE, 96, No. SM4, 1171-1200.

Benson, C. H. \& Daniel, D. E. (1990). Influence of clods on hydraulic conductivity of compacted. ASCE J. Geotech. Engng, 116, 12311248 .

Bhasin, R. N. \& Lovell, C. W. (1981). Distribution of porosity in compacted clays. Proc. 10th ISSMFE, Stockholm, 563-566.

Campbell, J. D. (1973). Pore pressures and volume changes in unsaturated soils. $\mathrm{PhD}$ dissertation, University of Illinois at Urbana-Champaign, p. 104

Croney, D. \& Coleman, J. D. (1954). Soil structure in relation to soil suction (pF). J. Soil Sci., 5, No. 1, 163-177.

Delage, P., Audiguier, M., Cui, Y-J. \& Howat, M. D. (1995). Microstructure of a compacted silt. Can. Geotech. Journal, 33, 150-158.

Elsbury, B. R., Daniels, D. E., Sraders, G. A. \& Anderson, D. C. (1990). Lessons learned from compacted clay liner. J. Geotech. Engng, ASCE, 116, No. 11, 1641-1660.

Fredlund, D. G. (1964). Comparison of soil suction and one-dimensional consolidation characteristics of a highly plastic clay. MSc thesis, Department of Civil Engineering, University of Alberta, Canada.

Hillel, D. (1982). Introduction to soil physics. New York: Academic Press. 
Krahn, J. \& Fredlund, D. G. (1972). On total, matric and osmotic suction. J. Soil Sci., 114, No. 5, 339-348.

Lambe, T. W. (1958). The engineering behavior of compacted clay. ASCE J. Soil Mech. Found. Div., 84, No. SM2, paper No. 1655, $1-35$.

Mickleborough, B. W. (1970). An experimental study of the effects of freezing on clay subgrades. MSc thesis, University of Saskatchewan, Canada.

Olson, R. E. \& Langfelder, L. J. (1965). Pore-water pressures in unsaturated soils. J. Soil Mech. Found., ASCE, 91, No. SM4, $127-160$.

Prapaharan, S., Altschaeffl, A. G. \& Dempsey, B. J. (1985). Moisture curve of compacted clay: mercury intrusion method. J. Geotech. Engng, 111, No. 9, 1139-1143.

Pufahl, D. E. (1970). Evaluation of effective stress components in nonsaturated soils. MSc thesis, University of Saskatchewan, Canada.

Russam, K. (1958). An investigation into the soil moisture conditions under roads in Trinidad, B. W. I. Géotechnique, 8, No. 1, 57-71.

Seed, H. B. \& Chan, C. K. (1959). Structure and strength characteristics of compacted clays. ASCE J. Soil Mech. Found. Div., 85, No. SM5, 87-129.

Seed, H. B., Mitchell, J. K. \& Chan, C. K. (1960). The strength of compacted cohesive soils. Proc. ASCE Research Conference on Shear Strength of Cohesive Soils, Boulder, Colorado, pp. 877-964.

Skempton, A. W. (1954). The pore pressure coefficients, A and B. Géotechnique, 4, No. 4, 143-147.

Sridharan, A., Altschaeffl, A. G. \& Diamond, S. (1971). Pore size distribution studies. J. Soil Mech. Found. Div., ASCE, 97, No. SM 5, $771-787$.

Tinjum, J. M. (1995). Soil-water characteristic curves for compacted fine-grained soils. Environmental Geotechnics Report No. 95-3, University of Wisconsin, Madison, USA.

Tinjum, J. M., Benson, C. H. \& Blotz, L. R. (1997). Soil-water characteristic curve of compacted clays. J. Geotech. Geoenviron. Engng, 123, No. 11, 1060-1069.

Vanapalli, S. K. (1994). Simple test procedures and their interpretation in evaluating the shear strength of an unsaturated soil. $\mathrm{PhD}$ thesis, University of Saskatchewan, Canada.

Wang, X. \& Benson, C. H. (1995). Infiltration and saturated hydraulic conductivity of compacted clay. J. Geotech. Engng, 121, No. 10, 713-722.

Weimer, H. F. (1972). The strength, resilience and frost durability characteristics of a lime-stabilized till. MSc thesis, University of Saskatchewan, Canada. 